\title{
Knowledge and Attitude of Recently Aborted Women in relation Family Planning Methods
}

Eman Elsayed Omer', Mona Ahmed Elsheikh², Samah Abd Elhaliem Saeid ${ }^{3}$ and Fatma Kamal Ali ${ }^{4}$

(1) Nursing specialist in the Health Administration-Kafr Shukr, Egypt, (2) Professor of Maternal and Gynecological Nursing, Faculty of Nursing, Ain Shams University, Egypt, (3) Assistant Professor of Obstetrics and Woman's Health Nursing, Faculty of Nursing, Benha University, Egypt and (4) Lecturer of Obstetrics and Woman's Health Nursing, Faculty of Nursing, Benha University, Egypt

\section{Abstract}

Background: Abortion is a common global health problem that affects women's health from all dimension of life. Aim of the study: The study aimed to assess knowledge and attitude of recently aborted women in relation family planning methods. Design: A descriptive study design was utilized to fulfil the aim of the study. Setting: The study was conducted at Obstetrical and Gynecological Outpatient Clinic affiliated to Benha University Hospital. Sampling: A Purposive sample included 240 women were recruited in the current study. Tools of data collection: Three tools were used to collect data, I: A structured Interviewing Questionnaire consisted of three parts, part (1) general characteristics of studied women, part (2) obstetrics and gynecological history and part (3) Family planning history. II: Women`s knowledge assessment sheet, and III: Modified Likert scale of recently aborted women`s attitudes in relation family planning methods Results: Less than half of the studied women had poor total knowledge scores regarding family planning methods. More than half of the studied women had a positive attitude regarding family planning methods. Conclusion: There was a highly positive statistically significant correlation between total knowledge and total attitudes scores regarding family planning methods. Recommendations: Intensive awareness educational programs should be prepared and implemented to raise women's awareness of family planning methods at all maternal centers.

Key words: Attitude, Family planning methods, Knowledge, Recently aborted women

\section{Introduction:}

Abortion is induced termination of pregnancy before fetal viability. The world health organization define abortion as pregnancy termination prior to 20 weeks gestation based up on the first date of last menstrual period or with a fetal weight of 500g (American College of Obstetricians \& Gynaecologists, 2018).

Every minute, there are averages of 255 births worldwide out of about 210 million pregnancies annually. Eighty million unplanned or unwanted pregnancies, and 1 in 2 are terminated before childbirth, accounting for more than 41 million abortions annually. About 47,000 women die each year from complications from abortion, $86 \%$ of which occur in developing countries. Abortion is a major risk for women and therefore a pressing public health issue (World Health Organization (WHO), 2019).

Abortion and family planning are closely related as abortion is a global health problem. There are 36 abortions annually per 1,000 women between the ages of 15 and 44 in developing regions, compared to 27 in developed regions (Bearak et al., 2020). According to the World Health Organization, around 22 million unsafe abortions are 
performed each year worldwide and an estimated 47,000 women die annually from complications arising from resorting to pregnancy termination practices (WHO, 2016).

Family planning plays a key role in the prevention of unintended pregnancy, including teen pregnancy. Preventing unintended pregnancy also reduces the incidence of abortion and improves birth outcomes. In addition, family planning information, education, and services reduce both the incidence and impact of sexually transmitted diseases through screening and treatment (Janani et al., 2019).

Post abortion family planning is the initiation and use of family planning methods at the time of management of an abortion or before fertility returns after the abortion. The World Health Organization estimates that globally, around 210 million women become pregnant each year, of which 75 million pregnancies end in either induced or spontaneous abortions or still births. Majority of these women do not want to become pregnant again in the near future. WHO also recommends spacing of at least 6 months between abortion and next pregnancy. Therefore, providing family planning services as a part of post abortion care can improve contraceptive acceptance and help break the cycle of repeated unwanted pregnancies

\section{(Bahawan, 2016).}

The role of nursing is expanded and strengthened as experts with profession fill the void in women's health care. Women can now receive a total assessment, planned treatment, education, counseling and support from the nurse. Additional training and professional developments within the nursing profession generally, mean that nurses now undertake many of the extended clinical roles previously performed by doctors. This increasing autonomy means that many families planning clinics now are run by "nurse only", where no doctor is present (Abebaw et al., 2019).

\section{Significance of the study:}

Family planning and abortion services are very closely connected. Both can a vital role in enabling women to control number of children (Cleland, 2019). A study of one thousand and twenty five women in aborted case from six villages were found in upper Egypt, It was found that 416 women have undergone abortion, were 265 abortions per 1000 live births, there have been around 25 million case of abortion $97 \%$ of them, in countries in Africa, Asia and Lantin America (WHO, 2017).

Family planning enables women to decide if they want to have children, being able to this has improved women's health and reduced maternal mortality rates. For example, having children too early or too close together can be detrimental for women's health. Family planning has also enabled women to enjoy the careers and lifestyles that they want. It has also allowed people to have smaller families so that they can provide more for the children that they do have (White et al., 2018). Therefor this study was conducted to assess knowledge and attitude of recently aborted women in relation family planning methods.

\section{Aim of the study:}

This study aimed to assess knowledge and attitude of recently aborted women in relation family planning methods.

\section{Research question:}

What is the level of recently aborted women's knowledge and attitude in relation family planning methods?

\section{Subjects and Method \\ Study design:}

A descriptive study design was utilized to fulfill the aim of the current study. 


\section{Study Setting:}

The study was conducted at obstetrical and gynecological outpatient clinic affiliated to Benha University Hospital.

\section{Sampling:}

Sample type: A Purposive sample

\section{Sample size:-}

The total number of aborted women attending to obstetrics and gynecological outpatient clinic at Benha university hospital at (2018-2019) years, was 605 aborted women (Benha university census, 2019). So, number of study subjects as calculated by the following formula were 240 .

\section{Sample technique:}

The researcher was visited the study setting, introduced herself and explained the purpose of the study to recently aborted women and this was repeated 3 times /week (Saturday- Monday - Wednesday) until the study sample was collected.

$$
\mathrm{n}=\frac{\mathrm{N}}{1+\mathrm{N}(\mathrm{e}) 2}
$$

Where:

$\mathrm{n}=$ sample

$\mathrm{N}=$ population

$\mathrm{e}=$ margin error $(0.05)$

\section{Tools of data collection:}

Three tools were used for data collection prepared by the researcher.

\section{Tool (1) A structured Interviewing} Questionnaire, and consist of three parts:-

Part (1): General characteristics of studied women`s.

Part (2): Obstetrics and gynecological history.

Part (3): Family planning history.

Tool (II): Women`s knowledge assessment sheet to assess women`s knowledge regarding family planning methods.

\section{Scoring system:-}

Each item was assigned a score of (2) give when answer was completely correct answer, a score (1) was given when the answer was incompletely correct and a score (0) was given when the answer was don't know. The total score of each section was calculated by summation of the scores of its items. The total scores for the knowledge was calculated by the addition of the total score of all sections.

The total knowledge score was classified as the following:

- $\operatorname{Good} \geq 75 \%$

- Average 50-<75\%

- Poor $<50 \%$

Tool (III): Modified Likert scale of recently aborted women's attitudes in relation family planning methods:

It was adapted from (Lincoln, 2018; Mekuriaw, 2015; Rahel, 2018) and modified by the researcher under the guidance of supervisors of the study. This scale included to assess women`s attitude regarding family planning methods.

\section{Scoring system:-}

Recently aborted women response was measured on three-point Likert scale that ranged from disagree (0), uncertain (1) and agree (2).

These scores were converted into percent score, the' attitude was considered positive if score $\geq 75 \%$ and negative if score $<75 \%$.

\section{Validity and reliability:}

The tool validity was done by three panel expertise in Maternity Nursing and Obstetrics specialty who reviewed the tools for clarity, relevance, comprehensive, 
applicability and reliability. The reliability was done by cronbach`s alpha coefficient test, which revealed that the knowledge assessment questionnaire's internal consistency was 0.81 and the internal consistency of the attitude assessment scale was 0.79 .

\section{Ethical consideration:}

- The aim of the study explained to each study recently aborted women before applying the tool to gain their confidence and trust.

- Considered the ethical side of the scientific research.

- Maintained self-esteem and dignity of recently aborted women.

- Each women of study was freedom to withdrawal at any time.

- Informed consent obtained from the study recently aborted women after explaining the purpose of the study.

- Did not contradict with cultural and religious.

- Positively aimed increasing the cultural awareness.

\section{Pilot study:}

Pilot study was carried out on $10 \%$ of the total sample ( 24 women) to test the clarity and applicability of the study tools and estimate the time required to fill the tools, since no modifications have been done, the pilot was included in the main sample.

\section{Field work:}

Data were collected from the beginning of May 2020 up to the end of December 2020, the period of collected data was 8 months and the researcher visited the pre mentioned setting from 9: am to 12: pm, three days /week (Saturday- Monday and Wednesday) average time taken to complete each interview ranged from 30- 45 minutes and average recently aborted women' number ranged between $2 \backslash 3$ recently aborted women /day.

- The researcher greeted the women, introduced herself, and explained purpose of the study.

\section{Statistical analysis:}

Computerized data entry and statistical analysis were done using Statistical Package for Social Science (SPSS) Version 22. Descriptive statistics were first applied (numbers, frequency, percentages, tables, figures, diagrams and standard deviation) then other statistical tests such as chi square. Correlation coefficient (r) was used to evaluate association between studied variables.

Results:

Table (1): Shows that more than half of the studied women $(52.1 \%)$ were in age group 20- years old with the mean age of $30.47 \pm 6.09$ years. More than one third of the studied women (39.6\%) had secondary education. Regarding occupation, more than half of the studied women (59.6\%) were house wife. Most of the studied women $(86.2 \%)$ were married. Less than two third of the studied women $(62.9 \%)$ and $(65.0 \%)$ were living in rural area and hadn't enough income respectively.

Table (2): Demonstrates that, more than half of the studied women $(57.9 \%)$ were marriage at age group 25- years old with the mean age of $23.97 \pm 4.33$ years. Less than half of the studied women $(41.6 \%)$ were multigravida multiparous, less than half of the studied women (48.4\%) had abortion for one time. Results showed that mean gestational age at recent abortion were $12.06 \pm 3$.25.As regards reasons for recent abortion, more than two third $(69.6 \%)$ of the studied women had 
fetal causes of abortion. Concerning nature of recent abortion, most of the studied women (85.0\%) had spontaneous abortion.

Figure (1): Clarifies that less than half $(41.5 \%)$ of the studied women had poor total knowledge scores regarding family planning methods.
Figure (2): Illustrates that more than half $(56.0 \%)$ of the studied women had positive attitude regarding family planning methods.

Table (3): Illustrates that there was a highly statistically significant correlation between total knowledge scores and total attitudes scores.

Table (1): Frequency distribution of a studied women regarding their general characteristics $(\mathrm{n}=\mathbf{2 4 0})$.

\begin{tabular}{|c|c|c|}
\hline General characteristics & No & $\%$ \\
\hline \multicolumn{3}{|l|}{ Age (in year) } \\
\hline $20-$ & 54 & 22.5 \\
\hline $27-$ & 125 & 52.1 \\
\hline$>35$ & 61 & 25.4 \\
\hline Mean \pm SD & \multicolumn{2}{|c|}{$30.47 \pm 6.09$} \\
\hline \multicolumn{3}{|l|}{ Educational level } \\
\hline Illiterate & 25 & 10.4 \\
\hline Primary education & 72 & 30.0 \\
\hline Secondary education & 95 & 39.6 \\
\hline University education & 48 & 20.0 \\
\hline \multicolumn{3}{|l|}{ Occupation } \\
\hline Working & 97 & 40.4 \\
\hline House wife & 143 & 59.6 \\
\hline \multicolumn{3}{|l|}{ Residence } \\
\hline Rural & 151 & 62.9 \\
\hline Urban & 89 & 37.1 \\
\hline \multicolumn{3}{|l|}{ Marital status } \\
\hline Married & 207 & 86.2 \\
\hline Divorced & 23 & 9.6 \\
\hline Widowed & 10 & 4.2 \\
\hline \multicolumn{3}{|l|}{ Monthly income } \\
\hline Enough & 84 & 35.0 \\
\hline Not enough & 156 & 65.0 \\
\hline
\end{tabular}


Table (2): Frequency distribution of studied women regarding their obstetrical history $(\mathbf{n}=\mathbf{2 4 0})$.

\begin{tabular}{|c|c|c|}
\hline Obstetrical history & No & $\%$ \\
\hline \multicolumn{3}{|l|}{ Age at marriage(in year) } \\
\hline$<25$ & 139 & 57.9 \\
\hline $25-$ & 81 & 33.8 \\
\hline$>35$ & 20 & 8.3 \\
\hline Mean \pm SD & \multicolumn{2}{|l|}{$23.97 \pm 4.33$} \\
\hline \multicolumn{3}{|l|}{ Gravida \& Parity } \\
\hline Primigravida Nulliparous & 76 & 31.7 \\
\hline Multigravida primiparous & 64 & 26.7 \\
\hline Multigravida Multiparous & 100 & 41.6 \\
\hline \multicolumn{3}{|l|}{ Number of abortion } \\
\hline One & 116 & 48.4 \\
\hline Two & 86 & 35.8 \\
\hline Three or more & 38 & 15.8 \\
\hline \multicolumn{3}{|c|}{ Gestational age at recent abortion } \\
\hline Mean \pm SD & \multicolumn{2}{|c|}{$12.06 \pm 3.25$} \\
\hline \multicolumn{3}{|c|}{ Reasons for recent abortion } \\
\hline Maternal causes & 73 & 30.4 \\
\hline Fetal causes & 167 & 69.6 \\
\hline \multicolumn{3}{|l|}{ Nature of recent abortion } \\
\hline Induced abortion & 36 & 15.0 \\
\hline Spontaneous abortion & 204 & 85.0 \\
\hline
\end{tabular}

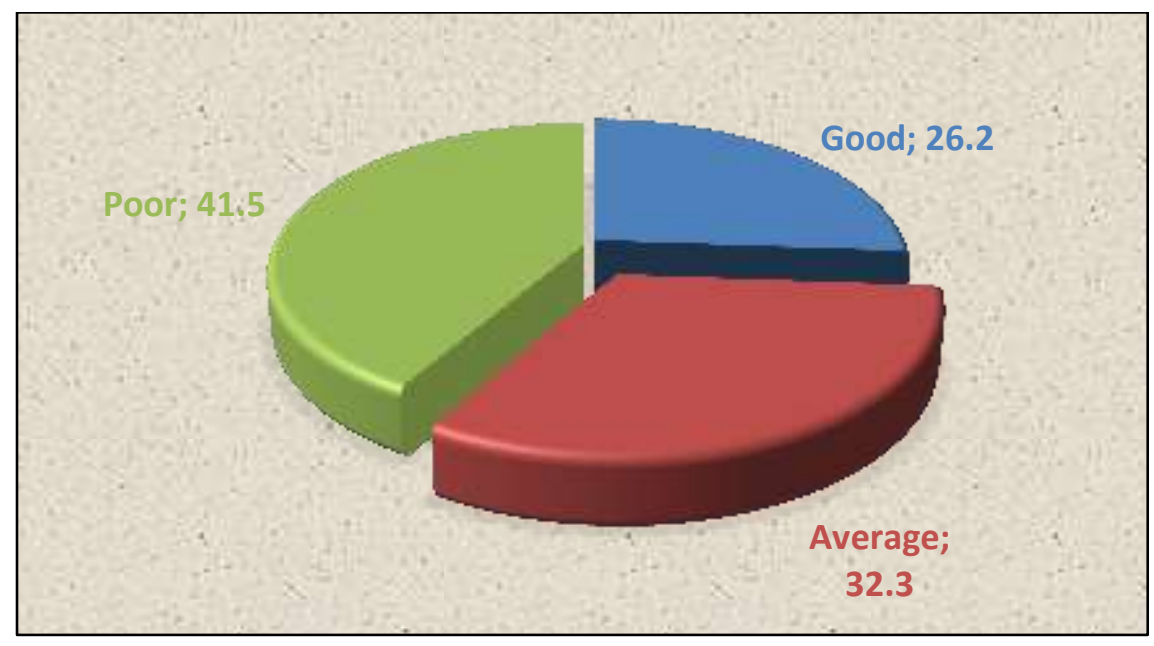

Figure (1): Percentage distribution of studied women regarding total knowledge scores about family planning methods $(\mathrm{n}=\mathbf{2 4 0})$. 


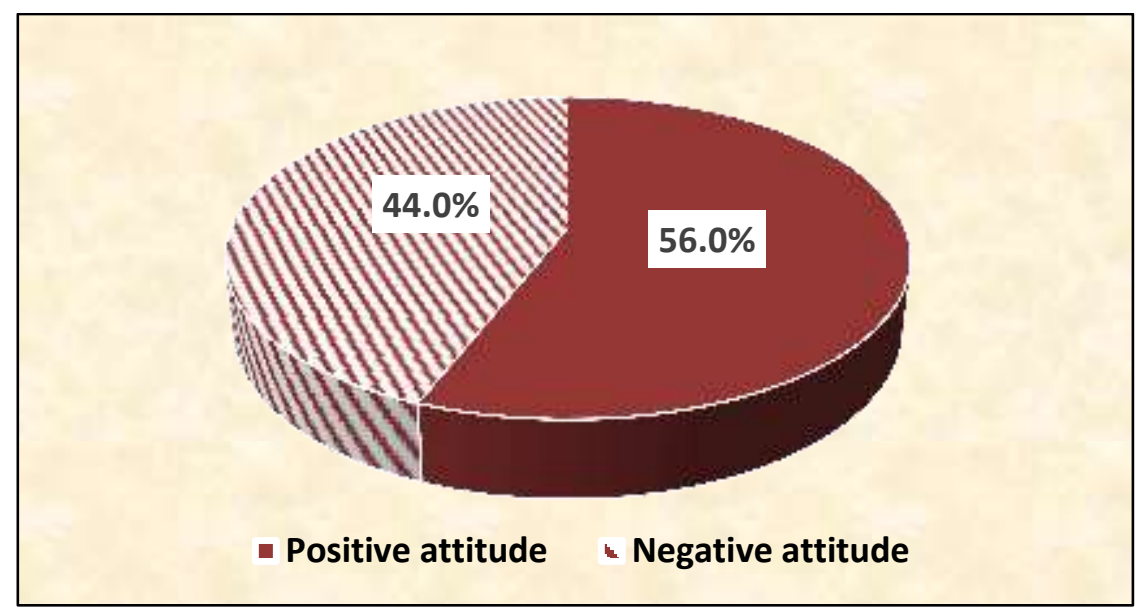

Figure (2): Percentage distribution of studied women regarding total attitude scores about family planning methods $(n=240)$.

Table (3): Correlation between total knowledge score and total attitude score among studied women $(n=240)$.

\begin{tabular}{|l|c|c|}
\hline \multirow{2}{*}{ Total attitude } & \multicolumn{2}{|c|}{ Total knowledge } \\
\cline { 2 - 3 } & $\mathbf{R}$ & P-value \\
\cline { 2 - 3 } & 0.57 & $0.000^{* *}$ \\
\hline
\end{tabular}

** Highly statistically significance

\section{Discussion:}

Family planning services and abortion are strongly linked, use of family planning methods use immediately after an abortion, the part of abortion care service which increases contraceptive use prevalence and reduces unintended pregnancies and unsafe abortion. The WHO guideline recommends a woman to wait at least six months after an abortion before getting pregnancy, important for women body time to regain its strength and prepare for healthy pregnancy (WHO, 2019).

This study aimed to assess knowledge and attitude of recently aborted women in relation family planning methods. The findings of this study answered the study question.

The discussion of the current study will be categorized under five main parts: Socio- demographic characteristic, Knowledge about family planning methods, Attitude regarding family planning methods, Relation between total knowledge as well as total attitude score and studied women demographic characteristics, Correlation between total knowledge score and total attitude score among studied women.

General characteristics of the studied women, the results of the present study showed that, more than half of the studied women were in age group 25- years old with the mean age of $30.47 \pm 6.09$ years, this finding comes in accordance with (Kumari , 2016) who conducted a study "Contraceptive knowledge, attitude and practice among reproductive age group women in a tertiary institute" and observed that most of the women fall in the mean age of $30.20 \pm 6.01$ years. On the other hand, the result disagreed with (Elsaid et al., 2017) who studied "Women's Knowledge, Practices and Attitude 
Regarding Family Planning" who reported that less than half of the studied women's age ranged from 30 to less than 40 years with mean age of $32.65 \pm 5.08$ years.

Regarding level of education, the present study showed that, more than one third of the studied women had secondary education, this finding agreed with (Egede et al., 2015) who studied "the prevalence, choices, and sources of contraceptive options among market women of reproductive age in Ebonyi State, Nigeria "and revealed that more than half of participant had secondary school education.

The results of the present study showed that most of the studied women were married, less than two third of the studied women were living in rural area, this result agreed with (Mahadeen et al., 2016) who conducted a study "Knowledge, attitudes and practices towards family planning among women in the rural southern region of Jordan" and reported that most of studied women were married and many of these women had lived in villages. In the researcher point of view, most of the studied women were married. It may be due to culture of early marriages of girls are very common in our Egyptian society especially in rural area.

Obstetrical history, the results of the present study showed that more than half of the studied women was marriage at age group 25- years old with the mean age of $23.97 \pm$ 4.33 years, this finding came in accordance with (Handady\&Naseralla, 2015) who conducted "A study to Assess Knowledge, Attitude and Practice of Family Planning among Married Women " who reported that more than half of women married at 20-30 years, this results disagreed with (Qazi et al., 2019) who reported that more than three quarters $(76.8 \%-62.2 \%)$ had $>3$ No of pregnancy and living children respectively. In the researcher point of view, this may be due to culture of had more children and more males are very common in our Egyptian society especially in rural area. The results of the present study showed that, more than two third of the studied women had fetal causes of abortion. This results nearly agreed with (Morris \& Prata, 2018) who conducted study about "Abortion history and its association with current use of modern contraceptive methods in Luanda" and reported that most abortion causes was fetal causes.

Conversely, the result disagreed with (Drew et al., 2020) who studied "Effectiveness level of contraceptive selection post-abortion" and reported that most of the client seeked induced abortion and most causes was for maternal causes.

Regarding women' knowledge. Health knowledge is an important element to enable women to be aware of health status and the importance of family planning methods. Family planning methods' knowledge are an important indicator of the reproductive health and unsafe post aborted period is the one of the most challenging and life threatening (Bhawan,2016).

Regarding total knowledge scores about family planning methods, the present study findings showed that, less than half of the studied women had poor total knowledge scores regarding family planning methods. In the researcher point of view these results may be due to their secondary education, lack of knowledge of technology and the internet because, most of them live in the rural area. The result was in accordance with (Prateek \&Saurabh, 2012) who studied "the extent of awareness regarding contraception among married women; a cross sectional descriptive 
study of four months duration among 180 married women were selected as study participants", and pointed out that, more than half of women were aware about contraceptive methods.

The result disagreed with (Kasa et al., 2018) who assessed "Knowledge, attitude and practice towards family planning among reproductive age women in a resource limited settings of Northwest Ethiopia" and reported that most of participant had good knowledge about family planning.

Regarding total attitude scores about family planning methods, the results of the present study showed that, more than half of the studied women had positive attitude regarding family planning methods and less than half of them had negative attitude regarding family planning method. In the researcher point of view, lack of knowledge may influence the attitude of aborted women toward family planning method.

This results was congruent with (Lincoln et al., 2018) who conducted a study about "Knowledge, Attitudes, and Practices of Family Planning among Women of Reproductive Age in Suva" reported that in general, the women expressed a positive attitude towards family planning, the result disagreed with (Wani, et al., 2019) who studied "Knowledge, attitude, and practice of family planning services among healthcare workers in Kashmir". The results reported that the women have negative attitude about family planning, whereas some have heard false and misleading information.

In relation to correlation between total knowledge score and total attitude score among studied women the present study findings showed that, there was a highly statistically significant correlation between total knowledge scores and total attitudes scores. In the researcher point of view the more knowledge of the women the more positive attitude regarding family planning method.

The result was congruent with (Royer et al., 2020) who studied "Family planning knowledge, attitudes, and practices among Somali and Congolese refugee women after resettlement to the United States" and showed a significant association between the number of family planning methods known and family planning attitude. In the researcher view of point this might be due to adequate knowledge about family planning enhancing attitude and practices about family planning methods.

The result disagreed with (Gambhir et al., 2018) who studied "A cross-sectional observational pilot study regarding status of contraceptive prevalence rate in family planning programmer in rural practice area of government medical college Patiala" and showed that knowledge and attitude of the study participants were related to family planning utilization although weak on correlation.

\section{Conclusion:}

Less than half of the studied women had poor total knowledge scores regarding family planning methods. More than half of the studied women had a positive attitude regarding family planning methods. There was a highly positive statistically significant correlation between total knowledge scores and total attitudes scores. Therefore, the study question was answered.

\section{Recommendations:}

- Intensive awareness educational programs should be implemented to raise 
women's knowledge regarding family planning methods at all maternal centers.

- Counseling for aborted women about the importance of periodic follow up.

- Simple illustrated guidelines about different family planning methods should be available for women in obstetrics and gynecology outpatient clinic.

\section{Further studies:}

- Replication of the study on larger sample size to get more accurate knowledge on the use and awareness of family planning of newly aborted women.

\section{Acknowledgements:}

We would like to thank all the aborted women to participate in the study and the nursing staff, during the study period and its share in the university study, and their cooperation during the period and scope of the large study that the supervisors write in this work.

\section{References:}

Abebaw, Y., Berhe, S., Abebe, S., Adefris, S., Gebeyehu, A., Gure, T., Asmare, B., \& Egziabher, M. (2019). Providers' knowledge on postpartum intrauterine contraceptive device (PPIUCD) service provision in Amhara region public health facility, Ethiopia. PLOS ONE; 14(4): PP.115.

\section{American College of Obstetricians} \&Gynecologists (2018). Early pregnancy loss. ACOG Practice Bulletin No. 200. Obstetrics\& Gynecology; 132:197207.

Bearak, J., Popinchalk, A., \&Ganatra, B. (2020). Unintended pregnancy and abortion by income, region, and the legal status of abortion: estimates from a comprehensive model. Lancet Glob Health. 2020 Sep; 8(9):e1152-e1161. Doi: 10.1016/S2214-109X (20)30315-6.

Bhawan, N. (2016). Post Abortion Family Planning, Ministry of Health\& Family welfare, $1^{\text {rd }}$, New Delhi -110101, India, p; 713.

Cleland, J., (2019). The complex relationship between contraception and abortion. Best Practice and Research Clinical Obstetrics and Gynaecology.

Darney, B. G., Fuentes-Rivera, E., Saavedra-Avendaño, B., Sanhueza-Smith, P., \& Schiavon, R. (2020). Contraceptive receipt among first-trimester abortion clients and postpartum women in urban Mexico. International Perspectives on Sexual and reproductive Health, 46(Supp lement 1), 35-43.

Drew, L. B., Mittal, M., Thoma, M. E., Harper, C. C., \& Steinberg, J. R. (2020). Intimate partner violence and effectiveness level of contraceptive selection postabortion. Journal of Women's Health, 29(9), 1226-1233.

Egede, J.O., Onoh, R.C., Umeora, O.U, Iyoke, C.A, Dimejesi, I.B., \& Lawani, L.O. (2015). Contraceptive prevalence and preference in a cohort of south-east Nigerian women, Patient preference and adherence 9(1):707-714. doi:10.2147/PPA.S72952.

Elsaid, A., Mohammed, F., Ahmed, H., Ibrahim, \&M. (2017). Women's Knowledge, Practices and Attitude Regarding Family Planning. Egyptian Journal of Health Care, 2017 EJHC Vol.8 No.2 147 EJHC.

Gambhir, P., Khaira, R., Singh, A., \& Raj, H. (2018). A cross-sectional observational pilot study regarding status of 
contraceptive prevalence ratein family planning programme in rural practice area of government medical college Patiala. Journal of Dental and Medical Sciences. 2018; $17: 35-40$.

Handady, S. O \&Naseralla, K. (2015). Knowledge, Attitude and Practice of Family Planning Among Married Women Attending Primary Health Center in Sudan,International Journal of Public Health Research,3(5):243-247.

Janani, A., Jahan, U., Verma,K., Gupta ,S., Gupta, R., Mahour, S.,\& Kirti ,N. (2019) . Awareness, attitude and practices of family planning methods in a tertiary care hospital. Uttar Pradesh, India, Report Contraception Obstetric Gynecology, 8(3):1319:1325.

Kasa, A., Tarekegn, M., \& Embiale, N. (2018). Knowledge, attitude and practice towards family planning among reproductive age women in a resource limited settings of Northwest Ethiopia. BMC Res Notes. 2018; 11:7-12.

Kumari, L. (2016). A Cross Sectional Study on Knowledge, Attitude and Practices of Contraceptives Methods and Unmet Needs among Reproductive Age Group Women in a Tertiary Care Health Institute. 3(2) 321-28.

Lincoln, J., Mohammadnezhad, M., \&Khan, S. (2018). Knowledge, Attitudes, and Practices of Family Planning among Women of Reproductive Age in Suva, Fiji in 2017. J Women's Health Care. 7(6) 7- 431.

Mahadeen A.I., Khalil A.O., 1 HamdanMansour A.M., Sato T. \&Imoto A. (2016). Knowledge, attitudes and practices towards family planning among women in the rural southern region of Jordan. Eastern Mediterranean Health Journal EMHJ • Vol. 18 No. 6 •
Mekuriaw, S., Mesay, R., Dereje, A., Kumalo, A., \&Feyissa, M. (2015). Knowledge, Attitude and Practice towards Safe Abortion among Female Students of Mizan-Tepi University, South West Ethiopia. J Women's Health Care. 4(5) 4275.

Morris, N., \& Prata, N. (2018). Abortion history and its association with current use of modern contraceptive methods in Luanda, Angola.419:45-55.

Prateek, S.S., \&Saurabh, R.S. (2012). Contraceptive practices adopted by women attending an urban health centre.U.S. National Library of Medicine, 12(4):416-21.

Qazi, M., Najmus, S., Sachin, G. (2019). Knowledge, attitude and practice of family planning among women of reproductive age group attending outpatient department in a tertiary centre of Northern India International Journal of Reproduction, Contraception, Obstetrics and Gynecology Qazi M et al. Int J Reprod Contracept Obstet Gynecol.;8(5):1775-1783 www.ijrcog.org.

Rahel, Y., Deriba, A., \&Asrat, M. (2018). Knowledge, Attitude and Practice towards Induced Abortion and Associated Factors among Female students in Yebu Secondary School, Jimma zone, South West Ethiopia. Glob J Reprod Med. 5(2): 555659.

Royer, P. A., Olson, L. M., Jackson, B., Weber, L. S., Gawron, L., Sanders, J. N., \& Turok, D. K. (2020). Family planning knowledge, attitudes, and practices among Somali and Congolese refugee women after resettlement to the United States. Qualitative health research, 30(3), 391-408.

Wani, R. T., Rashid, I., Nabi, S. S., \& Dar, H. (2019). Knowledge, attitude, and practice of family planning services among 
healthcare workers in Kashmir-A crosssectional study. Journal of family medicine and primary care, 8(4), 1319.

White, K., Hopkins, K., Grossman, D., \& Potter, J.E. (2018). Providing family planning services at primary care organizations after the exclusion of Planned Parenthood from publicly funded programs in texas: Early qualitative evidence. Health Serv Res. 2018; 53:2770-86.

World Health Organization (WHO), (2019): Global health observation data 2019.

World Health Organization. Department of Reproductive Health and research (WHO/RHR); Johns Hopkins Bloomberg School of Public Health/Center for Communication Programs (CCP), Knowledge for Health Project. Family Planning: A Global Handbook for Providers. 2018 update. Baltimore and Geneva: CCP and WHO; 2018.https://www. https://www.fphandbook.org/. Accessed February 27, 2019.

WHO, (2016): Unsafe abortion is still killing tens of thousands of women around the world - UN rights experts warn. International Safe Abortion Day Wednesday 28 September 2016. 


\section{معرفة ومواقف السيدات المجهضات حديثا فيما يتعلق بأساليب تنظيم الأسرة}

إيمان السيد عمر يوسف- مني أحمد الثيخ - سماح عبد الحليم سعيد ـ فاطمة كمال علي أحمد

يرتبط الإجهاض وتنظيم الأسرة ارتباطًا وثثيًا لأن الإجهاض بمثل مشكلة صحية عالمية. هناك بات عملية

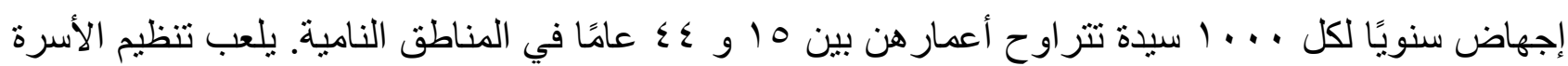

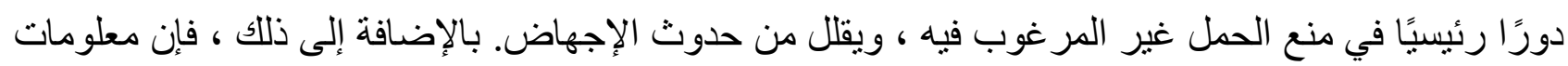

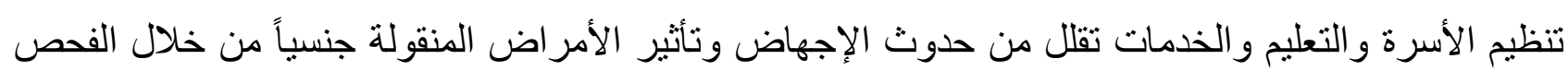
والعلاج. لذا هدفت الدراسة الي تقييم معرفة ومواقف السيدات المجهضات حديثا فيما يتعلق بأساليب تنظيم

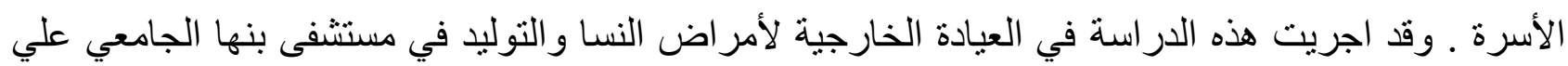

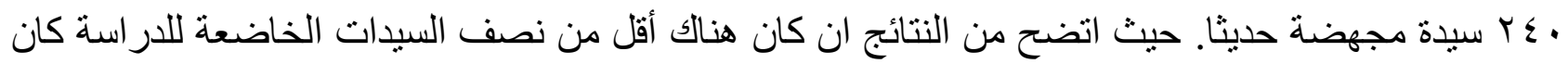
لايهن نقاط معرفية ضعيفه فيما يتعلق بأساليب تنظيم الأسرة و أكثر من نصف السيدات الخاضعة للار اسة كان

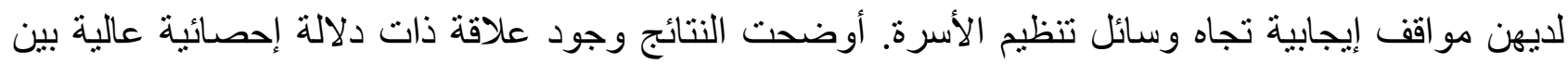

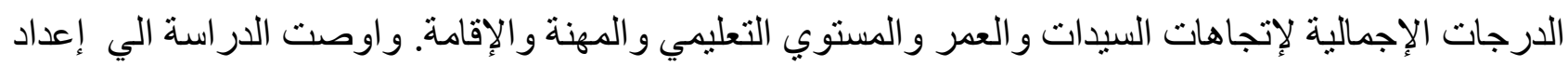

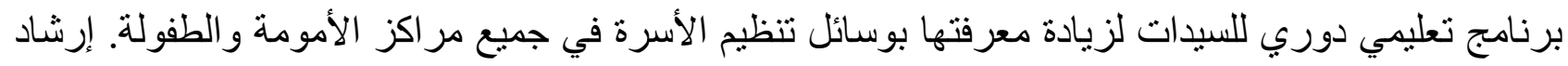
السيدات المجهضات حول أهمية المتابعة الدورية. 